\title{
El plan de igualdad debe negociarse con la representación legitimada legalmente y no por una comisión "ad hoc".
}

\author{
Pilar Rivas Vallejo \\ Catedrática de Derecho del Trabajo y de la Seguridad Social. Universidad de \\ Barcelona
}

Resumen: Los planes de igualdad deben ser objeto de negociación por la representación, unitaria o sindical, del personal de la empresa, en idénticos términos previstos para la negociación de convenios colectivos, sin que sean válidas ni comisiones de trabajo no representativas ni comisiones "ad hoc" únicamente previstas legalmente para la negociación de acuerdos muy concretos, y no uno de carácter y objetivos generales como es un plan de igualdad.

Palabras clave: Plan de igualdad. Comisión negociadora. Negociación. Legitimación para negociar.

Abstract: Equality plans must be subject to negotiation by the workers representatives, in the same terms provided for the negotiation of collective agreements, without being valid neither non-representative work commissions nor ad hoc commissions only foreseen legally for the negotiation of very specific matters, and not one of general scope and objectives such as an equality plan.

Keywords: Equality plan. Equality commission. Bargaining commission. Bargaining. Legitimation.

\section{Introducción}

La sentencia analizada estudia la hipotética negociación de planes de igualdad al margen de los canales legales previstos para ello, de acuerdo con la regulación de la Ley Orgánica de Igualdad y el título III del Estatuto de los Trabajadores, excluyendo por completo su validez si su aprobación no se inscribe en dicho marco legal, y, por consiguiente, la de los planes de igualdad elaborados por una comisión "ad hoc" no integrada por representantes de los trabajadores con legitimación para negociarlos. La resolución ha de contrastarse con las comisiones "ad hoc" que para la negociación de convenios colectivos permite el art. 5.3 del RD 901/2020, de 13 de marzo, para los supuestos de ausencia de representación, que, aunque exige igualmente su formación con representantes legitimados para negociar convenios colectivos, no rechaza de plano su propia existencia en tales casos especiales.

II. Identificación de la resolución judicial comentada

Tipo de resolución judicial: sentencia.

Órgano judicial: Tribunal Supremo, Sala Social.

Número de resolución judicial y fecha: sentencia núm. 95/2021, 26 de enero. 
Tipo y número recurso o procedimiento: recurso de casación núm. 50/2020.

ECLI:ES:TS:2021:350

Ponente: Excmo. Sr. D. Ricardo Bodas Martín.

Votos particulares: carece.

\section{Problema suscitado. Hechos y antecedentes}

\section{Legitimación para negociar planes de igualdad}

El problema que se suscita es, por una parte, la legitimación para negociar planes de igualdad, regida por las normas reguladoras de los convenios colectivos, explicitadas en el RD 901/2020, de 13 de octubre, que aprueba el reglamento sobre planes de igualdad, y, por otra parte, la validez de un plan de igualdad que se negoció con anterioridad a devenir obligatoria esta regla, no ya por no existir regulación explícita de los planes de igualdad, sino porque no concurría el presupuesto de hecho para la propia negociación, por inexistencia de órgano de representación de los trabajadores de la empresa. En concreto, se cuestiona si un plan de igualdad negociado con una comisión ad hoc en tales circunstancias y participado con posterioridad por el ya existente comité de empresa deviene nulo en cuanto se dan tales condiciones para permitir la negociación en el marco de las reglas previstas para los planes de igualdad, esto es, para los convenios colectivos. Por tanto, si aunque la negociación del plan inicial pudiera admitirse bajo tales extraordinarias circunstancias, el producto de la misma, el plan, deviene automáticamente nulo en cuanto aquellas cambian y ya es posible negociar bajo los parámetros legales ordinarios el plan con la representación unitaria o sindical de los trabajadores. $E$ incluso si tal modo extraordinario de negociar constituye asimismo una causa de nulidad del plan de igualdad ab initio, en tanto, según argumentan los demandantes, sí existía en el centro de trabajo de Sevilla una representación legal legitimada para negociar.

\section{Los hechos}

La empresa demandada cuenta con centros de trabajo en distintas provincias de la geografía española (Sevilla, Barcelona y Madrid, además de otros "pequeños lugares de trabajo dispersos por la geografía, que habitualmente se abren para el desarrollo de una obra concreta", en Cáceres, Córdoba y Málaga), y sus trabajadores con un sindicato propio (Candidatura Independiente Trabajadores de Ayesa, CITA2). Por el volumen de su plantilla, cuenta con plan de igualdad desde 2010 , que no se negoció con la representación de los trabajadores, por ser inexistente en aquella fecha, sino que por parte de la empresa se designó a cinco trabajadores para integrar lo que denominó "comisión de igualdad", encargada de elaborarlo. Por ello, a partir del año 2012, se suceden diversas propuestas de la representación legal del personal de la empresa para negociar un plan de igualdad, ante la negativa de la empresa, que aduce la existencia de un plan (el de 2010), que prevé su actualización periódica y que cuenta con informes de seguimiento anuales. De ello se deriva la denuncia presentada por el sindicato CCOO a la Inspección de Trabajo en octubre de 2014. Tras esta, en 2015 la empresa accede a que la representación legal del personal integre la comisión de seguimiento, que se ha reunido desde entonces hasta en seis ocasiones, surgiendo de tales reuniones una serie de propuestas de mejora del plan de igualdad.

La sentencia de la Sala Social de la Audiencia Nacional núm. 143/2019, de 10 de diciembre (ECLI:ES:AN:2019:4583), por la que se da respuesta al conflicto colectivo interpuesto por la representación legal de los trabajadores declara la nulidad del plan de igualdad citado, aprobado en 2010, por considerar que este debe iniciarse una vez existe representación del personal. En consecuencia, sostiene que el anterior plan debió sustituirse necesariamente por otro de carácter negociado, en lugar de admitir únicamente su mejora a través de la intervención del comité de empresa.

Resulta relevante considerar un hecho que ocupa el primero de los motivos del recurso de la empresa demandada, que es concretamente la composición del comité 
de empresa y la procedencia de algunos de sus miembros de la etapa previa a su constitución, lo que obligó a negociar con una comisión ad hoc ante la imposibilidad de hacerlo con representantes legitimados para ello. Concretamente, en la fecha en la que se aprobó el plan de igualdad, en la empresa únicamente existían tres trabajadores con tal condición de representantes del personal, integrados en el comité de empresa del centro de trabajo de Sevilla (centro mayoritario de la empresa), elegidos en una candidatura independiente. Solo más tarde tales trabajadores se integraron en la sección sindical estatal de CC.OO.

\section{Posición de las partes}

La empresa recurrente sostiene que existe error en la apreciación de la prueba basado en documentos que obran en autos, en los términos anteriormente descritos como hechos relevantes, así como infracción del art. 45.1 de la Ley Orgánica 3/2007, de 22 de marzo, para la igualdad efectiva de mujeres y hombres, en relación con los arts. 87, 88 y 89 ET, 24 CE y la jurisprudencia, emanada de las sentencias $7 / 2015$, de 24 de febrero de 2015, del Tribunal Constitucional y STS de 13 de septiembre de 2018 , rec. 213/2017. En esencia, sostiene la validez del plan de igualdad negociado en 2010 con una comisión ad hoc formada por cinco trabajadores, ante la imposibilidad de negociarlo con los representantes unitarios o sindicales legitimados, dada su inexistencia en la fecha indicada, y validada por el propio Estatuto de los Trabajadores, en tanto este permite en su art. 41 la negociación con comisiones ad hoc en el marco de la reforma introducida por el art. 5 del RDL 10/2010, de 16 de junio, de medidas urgentes para la reforma del mercado de trabajo, asimismo confirmada por la citada STS de 13 de septiembre de 2018 ante supuestos extraordinarios como el de autos. Aunque no se reproduce en el recurso, en el juicio celebrado ante la Sala Social de la Audiencia Nacional la empresa empleó un argumento adicional, conectado con la propia conducta del sindicato reclamante (CC.OO.) en tanto tardó cuatro años en cuestionar la validez del plan de igualdad, participando entretanto en diversas actividades implicadas en su seguimiento y, por tanto, mejora. $Y$ asimismo, que el contenido y elaboración del plan de igualdad se ajustan al marco legal por su suficiencia y por su diagnóstico previo.

Por su parte, la Federación de Servicios de CC.OO demandante impugna el recurso bajo el argumento de que las comisiones ad hoc no están previstas para la negociación de los planes de igualdad, que se rigen por las reglas de legitimación del art. 87.1 ET (la sentencia dice LRJS por error). Y, en segundo lugar, porque incluso en el momento inicial de la negociación del plan existía, arguyen, representación unitaria legitimada para ello, lo que excluía la posibilidad de negociar con ninguna otra comisión que no fuera la que regula el art. 87.1 ET.

Finalmente, el Ministerio Fiscal en su informe interesa la improcedencia del recurso de casación sobre la base del art. 87.1 ET, pues no cabe negociación del plan de igualdad con otra representación que no sea la que ordena tal precepto.

\section{Normativa aplicable al caso}

Estatuto de los Trabajadores, arts. 85.2, 87.1 y 17.5.

Ley Orgánica $3 / 2007$, de 22 de marzo, para la igualdad efectiva entre mujeres y hombres, arts. 45 y 46 (redacción ex RD-ley 6/2019, de 1 de marzo).

No es de aplicación a la fecha de los autos el RD 901/2020, de 13 de octubre, por el que se regulan los planes de igualdad.

\section{Doctrina básica}

\section{Negociación de planes de igualdad}

La resolución analizada sintetiza la doctrina de la Sala IV en cuanto a la forma y legitimación para negociar planes de igualdad, que se asimila a la prevista para convenios colectivos, sin recurrir a su identificación como tales. Así, sostiene que: 
- Los planes de igualdad deben ser negociados con los representantes unitarios o sindicales de los trabajadores, que acrediten la legitimación, exigida por el art. 87.1 ET, porque así lo requiere el art. 85.2 ET (STS 11 de marzo de 2014, rec. 77/2013; 9 de mayo de 2017, rec. 85/2016; 14 de febrero de 2017, rec. 104/2016 y 13 de septiembre de 2018, rec. 213/2017, excluyendo la aprobación por mera imposición unilateral por el empresario en caso de inexistencia de acuerdo. La STS 13 de septiembre de 2018, rec. $213 / 2017$, habilita el despliegue unilateral de un plan de igualdad por parte de la empresa (como "obiter dicta"), de forma "provisional" y como supuesto "límite", la que se justifica por la concurrencia de "circunstancias excepcionales", como "el bloqueo negociador imputable exclusivamente a la contraparte"; "la negativa de la misma a negociar" o "la ausencia de cualquier tipo de representación".

- No existe opción posible en el art. 45.3 LOI entre negociar el plan o implantarlo unilateralmente si la negociación colectiva fracasa, según se afirma en la STS 9 de mayo de 2017, rec. 85/2016. Dicha doctrina debería matizarse de acuerdo con los casos admitidos legalmente, como sucede en el ámbito de las administraciones públicas o los extraordinarios anteriormente mencionados.

- Los planes de igualdad deben ser obligatoriamente negociados en función del tamaño de la empresa (en empresas de más de doscientos cincuenta trabajadores, se afirma en la sentencia, en cuanto los hechos juzgados son anteriores al cambio normativo que los reduce a cincuenta trabajadores) 0 por disposición expresa del convenio colectivo aplicable. Pero en todos los casos la legitimación para su negociación corresponde a los mismos sujetos y nunca a una comisión ad hoc (STS 14 de febrero de 2017, rec. $104 / 2016$, que afirma literalmente que el "...plan de igualdad ha de contar con el acuerdo de la empresa y los representantes legales de los trabajadores, lo que no permite sustituir el mismo por un acuerdo entre la empresa y una comisión de trabajadores creada ad hoc para su negociación").

- La relevancia de los objetivos perseguidos por la ley para asegurar la igualdad efectiva entre mujeres y hombres justifica que deba "acometerse necesariamente por los sujetos legitimados para la negociación de los convenios de empresa, de conformidad con lo dispuesto en el art. 45 LO $3 / 2007$, de 22 de marzo, en relación con los arts. $17.5,85.2,87,88$ y 89 ET", para asegurar su eficacia general.

- No es factible sustituir a los representantes unitarios o sindicales de los trabajadores por una comisión ad hoc, fórmula negociadora excepcional, habilitada legalmente para solventar los supuestos de inexistencia de representación legal de los trabajadores, y reservada a determinadas materias, "anudadas a medidas de flexibilidad interna y externa, como los períodos de consulta de la movilidad geográfica (art. 40 ET) y las modificaciones sustanciales colectivas (art. $41 \mathrm{ET}$ ), la suspensión de contratos y la reducción de jornada (art. $47 \mathrm{ET}$ ), el despido colectivo (art. $51 \mathrm{ET}$ ) y la inaplicación de convenio (art. 82.3 ET)", no extrapolable a otros casos como la negociación de convenios colectivos o de planes de igualdad (STS 28 de junio de 2017, rec. 203/2016, que afirma que "... representación ad hoc no aparece entre los sujetos legitimados para negociar un convenio de empresa", porque "la legitimación de las 
comisiones ad hoc solo es válida en los casos expresamente contemplados por la norma").

\section{Por qué es una comisión de trabajo y no una comisión negociadora}

La sentencia comentada sostiene que no cabe hablar en el caso analizado ni siquiera de una comisión de las reguladas en los arts. 40, 41, 47, 51 y 82.3 ET y a cuyo concepto y existencia se acoge la recurrente, toda vez que tales comisiones ad hoc no solo están previstas únicamente para determinadas materias, como se ha citado, sino que en su propia creación falla el presupuesto básico para considerarlas comisiones negociadoras, en tanto sus integrantes no son libremente designados por la propia plantilla de la empresa, sino por la dirección de la empresa misma, lo que excluye la existencia de un proceso negociador. En este caso, se trata más bien de un encargo realizado por la empresa a una comisión de trabajo (creada por ella misma) y no una comisión negociadora.

En definitiva, para que aun en supuestos extraordinarios de falta de representación, lo cual no acontece en este caso, puesto que sí existía una representación de tres de los cinco componentes del comité de empresa de Sevilla, no invitados a participar en tal comisión, "toda vez que la ausencia de interlocutor válido para la negociación no comporta, de ningún modo, que pueda imponerse unilateralmente el Plan por la empresa, aunque se sometiera a un remedo de negociación con cinco trabajadores, que se representaban a sí mismos, en el mejor de los casos".

En el caso analizado tampoco concurren las condiciones extraordinarias que, bajo la STS 13 de septiembre de 2018 se admiten como supuestos límite para considerar el despliegue unilateral del plan de igualdad por parte de la empresa, puesto que no existe bloqueo negociador, negativa a negociar o ausencia total de representación de los trabajadores. Tales indicios son indicativos, a juicio de la Sala IV, de un deliberado propósito de la empresa de imponer unilateralmente el plan de igualdad, eludiendo todo intento de negociación con la representación del personal de la plantilla, y, por tanto, de un incumplimiento claro de lo dispuesto en el art. 45 de la Ley Orgánica $3 / 2007$, de 22 de marzo, en relación con los arts. 17, 85.2, 87, 88 y 89 ET y justifica la nulidad del plan así adoptado.

\section{Parte dispositiva}

La sentencia declara la nulidad del plan de igualdad adoptado por la empresa mediante el encargo de su elaboración a una comisión de trabajo, por no ser esta una comisión negociadora ni representativa del personal de la empresa, confirmando así la sentencia de instancia, dictada en conflicto colectivo por la Sala Social de la Audiencia Nacional.

\section{Pasajes decisivos}

El fundamento de derecho tercero, apartados segundo y tercero, condensan la doctrina de la Sala IV del Tribunal Supremo (apartado segundo) y su aplicabilidad al caso enjuiciado (apartado tercero). Son reseñables los siguientes párrafos:

"La Sala, en relación con la elaboración de los planes de igualdad en empresas de más de 250 trabajadores, ha venido sosteniendo reiteradamente que deben ser negociados con los representantes unitarios o sindicales de los trabajadores, que acrediten la legitimación, exigida por el art. 87.1 ET, porque así lo requiere el art. 85.2 ET (STS 11 de marzo de 2014, rec. 77/2013; 9 de mayo de 2017, rec. 85/2016; 14 de febrero de 2017, rec. 104/2016 y 13 de septiembre de 2018, rec. 213/2017, donde advertimos que, la aprobación del plan de igualdad exige alcanzar un acuerdo con la representación legal de los trabajadores, sin que quepa su imposición unilateral por el empresario, cuando no haya acuerdo". (apartado 2, primer párrafo)

"En STS 9 de mayo de 2017, rec. 85/2016, hemos mantenido que, "...el número 3 del artículo 45 de la Ley 3/2007 no establece la opción que dice la empresa recurrente: 
negociar un "plan de igualdad" o implantarlo unilateralmente si la negociación colectiva fracasa".

"En STS 14 de febrero de 2017, rec. 104/2016, hemos descartado que la negociación de los planes de igualdad pueda encomendarse a una comisión ad hoc, puesto que el "...Plan de igualdad ha de contar con el acuerdo de la empresa y los representantes legales de los trabajadores, lo que no permite sustituir el mismo por un acuerdo entre la empresa y una comisión de trabajadores creada ad hoc para su negociación" (apartado 2, segundo párrafo)

“...como hemos sostenido en STS 28 de junio de 2017, rec. 203/2016, donde precisamos que "...representación ad hoc no aparece entre los sujetos legitimados para negociar un convenio de empresa", porque "la legitimación de las comisiones ad hoc solo es válida en los casos expresamente contemplados por la norma", lo que no sucede con la negociación de los planes de igualdad, cuya eficacia para el cumplimiento de los objetivos perseguidos, requiere que se negocien con representantes que aseguren su eficacia general". (apartado 3, primer párrafo)

“... No es cierto, que nuestra STS 13 de septiembre de 2018, rec. 213/2017, habilite la imposición unilateral de un plan de igualdad por parte de la empresa, puesto que la sentencia se limita a citar, a título de ejemplo y como "obiter dicta", para un posible despliegue unilateral de un plan de igualdad, que la sentencia califica significativamente como "provisional", lo que considera como un supuesto "límite", siempre que concurran "circunstancias excepcionales", como "el bloqueo negociador imputable exclusivamente a la contraparte"; "la negativa de la misma a negociar" o "la ausencia de cualquier tipo de representación"'. (apartado 3, cuarto párrafo)

\section{Comentario}

\section{Naturaleza del plan de igualdad}

Los planes de igualdad se definen en el art. 8 RD 901/2020 como un conjunto ordenado de medidas adoptadas después de realizar un diagnóstico de situación, tendentes a alcanzar en la empresa la igualdad de trato y de oportunidades entre mujeres y hombres y a eliminar la discriminación por razón de sexo.

La sentencia objeto de recurso de casación define de manera explícita la naturaleza de convenio colectivo que la dicción actual de los arts. 45 y 46 de la Ley Orgánica 3/2007, de 22 de marzo, y su reglamento de desarrollo, el RD 901/2020, de 13 de octubre (en vigor desde el 14 de enero, esto es, días antes de la fecha de la sentencia analizada) afirman con claridad, remitiendo su negociación a la propia regulación de los convenios colectivos, ex art. 85.1 ET (STS núm. 403/2017). De igual modo, el art. 45.2 LOI no deja lugar a dudas al afirmar que "las medidas de igualdad a que se refiere el apartado anterior deberán dirigirse a la elaboración y aplicación de un plan de igualdad", previsión que se repite en el art. 2.2 del RD 901/2020.

Tanto es así, que el reglamento de desarrollo de los planes de igualdad remite a la regulación de la negociación colectiva tanto la legitimación para su negociación como el procedimiento aplicable, y remitiendo al título III del Estatuto de los Trabajadores como norma supletoria "todo aquello no regulado expresamente...", "todo ello sin perjuicio de las disposiciones que establezcan al respecto los convenios colectivos, dentro del ámbito de sus competencias" (art. 1). En años anteriores, la Sala IV del Tribunal Supremo efectuaba una distinción entre convenios de empresa y convenios de ámbito superior, refiriendo la comisión negociadora únicamente al ámbito superior (la STS de 11 marzo 2014 [rcud. núm. 77/2013] sostenía que, "cuando es un convenio colectivo de empresa el que establece las pautas para conseguir la igualdad, su desarrollo, la redacción del plan de igualdad, puede hacerse mediante una comisión de ejecución o administración, cual entendió esta Sala en sus sentencias de 25-6-2010 [R. 78/2009] y 24-1-2012 [R. 22/2011], mientras que si se trata de un convenio de ámbito superior, la implementación de esas medidas a través del plan de igualdad debe realizarse mediante una comisión negociadora"). Pero en el actual 
marco legal la comisión negociadora debe referirse igualmente al plan de igualdad de empresa.

La ya citada sentencia de la Audiencia Nacional alude a su previa resolución de 26 de junio de 2019 (proc. 101/2019), en la que literalmente se afirma que "la simple lectura de los preceptos examinados permite concluir, sin ningún género de dudas, que la elaboración de los planes de igualdad es una manifestación propia de la negociación colectiva, como defendimos en SAN 16-09-2015, proc. 267/15, confirmada por STS 9-05-2017, rec. 85/16, que se encomienda a las comisiones negociadoras de la empresa, como se deduce expresamente del inciso final del apartado primero del art. 46 LO 3/2007, las cuales deben asegurar la representatividad de todos los trabajadores de la empresa en los términos previstos en los arts. 87, 88 y 89 ET". Y, asimismo, refiere su ámbito a dos marcos diferentes: por un lado, la empresa y, por otro lado, el ámbito superior a la empresa, como espacios naturales para su negociación, según infiere del art. 85, apartados primero y segundo, del ET, por su eficacia erga omnes y, por tanto, más garantista, en tanto "se pone en juego la igualdad efectiva entre mujeres y hombres en el seno de la empresa, asegurados por el art. $14 \mathrm{CE}$, en relación con los arts. 4.2.c, 17.5 ET, cuya protección es más efectiva mediante la negociación colectiva estatutaria, puesto que despliega efectos normativos erga omnes".

En esa definición de los espacios reservados a la negociación de planes de igualdad, la Audiencia Nacional traza una dicotomía entre el ámbito de la empresa y el superior a la misma. Ahora bien, no se trataría tanto de planes de igualdad como de medidas de igualdad, de suerte que los planes tienen un espacio natural definido por la empresa, mientras que los ámbitos superiores a esta pueden prever medidas destinadas a favorecer la igualdad entre mujeres y hombres en cuestiones que puedan ser comunes en un ámbito como es un sector, pero que necesariamente los planes de empresa deberán concretar para acomodar las medidas que deban contener al diagnóstico de situación que, igualmente, debería individualizarse en el ámbito propio de la empresa para ser lo preciso y fidedigno que un diagnóstico de sector difícilmente podría ser, amén de especialmente costosa su elaboración, en términos de recursos y de tiempo y, obviamente, de precisión del análisis. Convenio sectorial y plan de igualdad de empresa están destinados a coordinarse y a definir espacios de regulación necesariamente, de suerte que el plan de igualdad de empresa pueda concretar algunas de las cuestiones que el convenio colectivo sectorial o en todo caso de ámbito superior haya previsto con un posible carácter más genérico.

\section{Aplicación de las reglas de negociación de los convenios colectivos}

El art. 45.1 de la LO 3/2007 (LOI) alude explícitamente a "negociar, y, en su caso acordar con los representantes legales de los trabajadores" las "medidas dirigidas a evitar cualquier tipo de discriminación laboral entre mujeres y hombres, lo que sitúa la elaboración de los planes de igualdad en los que puedan plasmarse tales medidas planificadas en el ámbito de la negociación colectiva.

La negociación de los planes de igualdad sigue las previsiones reguladoras de la negociación colectiva en los supuestos en los que aquellos sean obligatorios, esto es, en las empresas con plantillas iguales o superiores a cincuenta trabajadores y supuestos ya anteriormente previstos a la entrada en escena del RD 901/2020, de 13 de octubre, regulador de los planes de igualdad, en el art. 45.2 de la Ley Orgánica $3 / 2007$, de 22 de marzo, para la igualdad efectiva de mujeres y hombres. La negociación voluntaria del plan fuera de estos supuestos puede soslayar tales presupuestos legales, bastando la consulta a la representación legal del personal (cuya opinión tampoco será vinculante), según entiende la sentencia de la Audiencia Nacional núm. 23/2020, de 24 de febrero, que, por tanto, permitiría avalar la aprobación unilateral por las empresas en tales supuestos, amén de los que citan la propia resolución comentada de 26 de enero de 2021 por razón de su carácter extraordinario (la ya citada STS 13 septiembre 2018, rec. 213/2017, sostiene con carácter extraordinario que, "aunque pudiera concluirse que un bloqueo negociador por parte de los representantes de los trabajadores podría erigirse en justificación 
razonable del incumplimiento de la obligación de contar con un plan de igualdad o, al límite, como justificación de la implementación unilateral de un plan de igualdad provisional, lo cierto es que para ello deberían darse circunstancias excepcionales"). El propio art. 2 del reglamento de desarrollo avala esta interpretación en sus apartados 2 y 3 , admitiendo la simple consulta a la representación legal del personal en los casos meramente voluntarios. En todo caso, el citado reglamento regulador de los planes de igualdad exige su registro y aplicación una vez adoptado, con independencia de su origen y naturaleza.

No obstante, la ya citada STS 13 septiembre 2018, rec. 213/2017, sostiene con carácter extraordinario que, "aunque pudiera concluirse que un bloqueo negociador por parte de los representantes de los trabajadores podría erigirse en justificación razonable del incumplimiento de la obligación de contar con un plan de igualdad o, al límite, como justificación de la implementación unilateral de un plan de igualdad provisional, lo cierto es que para ello deberían darse circunstancias excepcionales".

Ahora bien, sea cual sea el modo de aprobarse el plan de igualdad, en todos los casos este deberá adaptarse, por la vía de la negociación prevista para su creación ex novo, a la nueva realidad legal (en el plazo habilitado al efecto, D.T. única RD $901 / 2020$, de acuerdo con la D.T. $12^{\mathrm{a}}$ LOI), obviamente al margen del criterio de designación utilizado por la empresa recurrente, y con inclusión de la negociación del diagnóstico de situación previo, objeto de negociación por la comisión negociadora constituida para la elaboración del plan.

Su aprobación al margen de este marco legal determina la nulidad del plan, como señala la sentencia objeto de comentario y otras anteriores de la misma sala (STS núm. 403/2017, de 9 de mayo, y STS núm. 832/2018, de 13 de septiembre). De igual modo, es nulo el plan, aun negociado, si no se negoció con los legitimados (la STS núm. 126/2017, de 14 febrero [rcud.104/2016], niega validez al plan negociado con los trabajadores sin ajustarse a las reglas de legitimación negocial), incluso si la comisión ad hoc está formada por distintos sujetos legitimados para ello, pero al margen de las reglas del título III del Estatuto de los Trabajadores. Ahora bien, con posterioridad, el art. 5.3 RD 901/2020 ha admitido la constitución de una comisión negociadora ad hoc precisamente para salvar los casos en los que no exista órgano de representación, lo que salvaría, si nos atuviéramos al argumento de la empresa recurrente (la inexistencia de tal representación en la empresa), el caso analizado, exigiéndose, sin embargo, que tal comisión esté integrada por los sindicatos más representativos y los sindicatos representativos del sector al que pertenezca la empresa y que cuenten con legitimación para formar parte de la comisión negociadora del convenio colectivo de referencia, aunque no respondan todos ellos a la convocatoria de la empresa en un periodo de diez días.

Finalmente, en relación con esta última cuestión, si bien se admite la administración y desarrollo de planes de igualdad a través de comisiones de convenio donde únicamente participen los sindicatos firmantes, sin que esta práctica se considere vulneradora del derecho de libertad sindical de los no incluidos, si tal comisión acometa medidas negociadoras, deberán participar todos los sujetos legitimados para la negociación, sean unitarios o sindicales (STS 25 junio 2010, rec. 78/2009, y de 9 mayo 2017, rec. 85/2016).

\section{La preexistencia de planes de igualdad al nuevo marco legal}

La última de las cuestiones que suscita la resolución analizada es la validez del plan de igualdad previo al cambio legislativo que supone el RD-ley 6/2019, de 1 de marzo ( $y$, por supuesto el posterior RD 901/2020), acordado antes de la transformación que esta reforma ha supuesto en este instrumento para la igualdad en el ámbito de las empresas. Por una parte, en la sentencia en cuestión se alude, aunque no se resuelve, por fallar el presupuesto básico del debate, que es la elaboración del plan al margen de todo tipo de negociación (pues se elaboró por una comisión de trabajo, aun cuando esta estaba integrada por trabajadores, si bien bajo la 
designación directa de la dirección de la empresa), a la nulidad sobrevenida de los planes de igualdad previamente aprobados.

En primer lugar, el propio RD 901/2020 resuelve que tales planes deberán adaptarse al nuevo marco legal, con independencia de la tipología en la que puedan encuadrarse (voluntarios u obligatorios, negociados o unilaterales...), disponiendo para ello un plazo límite (de tres meses para constituir la comisión negociadora y otros doce para llegar al acuerdo) a partir de su entrada en vigor (14 de enero de 2021). Ello implica que no será válido ni el diagnóstico que se hubiera realizado con anterioridad ni, mucho menos, la planificación en la que consista el plan de igualdad, aun cuando pudiera haber sido de negociación uno y otro dentro de los cauces previstos para la negociación colectiva, a no ser que cumplan todos los parámetros introducidos por el RD-ley 6/2019 en los arts. 45 y 46 LOI y en su desarrollo reglamentario. Por tanto, deberán adaptarse en sus contenidos y en la forma de negociar incluso el diagnóstico, lo que plantea la nulidad de los planes que no se ajusten a esta nueva realidad legal, como se plantea en la sentencia de la Audiencia Nacional núm. 134/2019, de 12 de noviembre. Lógicamente, deviene nulo todo diagnóstico que no se ajuste a los nuevos parámetros, actuando dicha nulidad en cascada sobre todo el proceso posterior y el propio acuerdo que contiene el plan aprobado.

Por otra parte, el nuevo panorama legal derivado de las reformas indicadas plantea otro tipo de cuestiones que solo se apuntan en los hechos recogidos en la sentencia comentada, sin mayor profundización en ellos en tanto que no son el objeto de la litis, pero que resulta de interés destacar. En concreto, se describen las sucesivas mejoras y aportaciones al plan de igualdad litigioso a través del mecanismo de seguimiento introducido, lo que permite traer a colación la hipotética validez de estas situaciones transicionales respecto al diagnóstico de situación, a las que se refiere la sentencia de la Audiencia Nacional núm. 134/2019, de 12 de noviembre, respecto de un proceso de negociación ya avanzado. En todos los casos, el diagnóstico abocado a la planificación de las medidas oportunas en el plan de igualdad exige su actualización, no solo en cuanto a los contenidos que exige pactar el art. 8 del RD 901/2020 en relación con el art. $46.3 \mathrm{LOI}$ (que no se cumplía en el caso de autos), sino por la propia necesidad de contar con dicho acuerdo respecto de los mismos.

\section{Apunte final}

La STS de 26 de enero de 2021 se refiere con precaución y subrayando el carácter extraordinario y "provisional" de los supuestos que permiten adoptar unilateralmente un plan de igualdad, entre los que no se encuentra el supuesto de autos. Entre ellas sí se citan, recogiendo el obiter dicta de la STS 13 de septiembre de 2018, rec. 213/2017, "el bloqueo negociador imputable exclusivamente a la contraparte", "la negativa de la misma a negociar" o "la ausencia de cualquier tipo de representación". Esta última ha dejado de constituir una excepción al amparo del art. 5.3 del RD $901 / 2020$, que la sustituye por la creación de una comisión ad hoc, semejante a la prevista en otras cuestiones a lo largo del ET. Ahora bien, las otras causas siguen sin contar con una respuesta explícita en el reglamento regulador de los planes de igualdad, que mantiene la vigencia de tal doctrina, de especial significancia en el ámbito de las administraciones públicas, donde la DA $7^{\mathrm{a}}$. de la Ley Básica del Empleado público (aprobada por Real Decreto Legislativo 5/2015, de 30 de octubre) dispone que las administraciones públicas están obligadas a adoptar medidas dirigidas a evitar cualquier tipo de discriminación laboral entre mujeres y hombres, así como elaborar y aplicar un plan de igualdad a desarrollar en el convenio colectivo o acuerdo de condiciones de trabajo de personal funcionario que sea aplicable, en los términos previstos en el mismo. En particular, porque el artículo 38.7 EBEB dispone expresamente que, en caso de no producirse acuerdo y, una vez agotados, en su caso, los procedimientos de solución extrajudicial de conflictos, corresponderá a los órganos de gobierno de la administración pública correspondiente establecer las condiciones de trabajo de los funcionarios. En tales casos, ese carácter provisional que la resolución comentada atribuye a una solución del carácter extraordinario que predica sin duda quedaría desplazado y suplantado por la válida aprobación del plan 
por la administración pública implicada. En el supuesto analizado (el contexto de una empresa privada), esta opción dejaría paso a un periodo de transición en tanto se pudiera llegar a una verdadera negociación. 